\title{
Introduction: HOPE
}

The articles published in Part One of the present issue of Studia Litteraria Universitatis Iagellonicae Cracoviensis are the fruit of the second student-doctoral NEWstories conference organised by doctoral candidates from the Jagiellonian University's Institute of English Studies. The conference entitled Shades of Hope in 20th-and 21st-Century Literature, gathering young researchers from Polish and European universities, was held on 7th March 2020 and happened to be one of the last events of this kind before the national lockdown was introduced in Poland on 12th March. Undoubtedly, it was significant to discuss such a theme as the pandemic was about to redefine our perception of hope. As the papers presented at the conference revealed, it is a challenging task to seek glimmers of hope amid many disheartening topics ranging from various facets of crisis to constant violent conflicts. Yet, it is also a rewarding endeavour to pursue the quest for hope in contemporary literature.

The conference plenary lecture delivered by Dr Nonia Williams from the University of East Anglia focused on the possibilities for hope in Doris Lessing's writing concerned with women's ageing. Even though the theme of ageing is more of the reverse of hope, as can be seen in pessimistic stories of decline as well as paradoxes created at the meeting point of "ageing" and "the contemporary," Dr Williams elaborated on Lessing's techniques by means of which a more positive perspective on concerns related to the elderly may be sought. While narratives on ageing offer little hope, Lessing's use of form and narration opens up space for ambiguity and the sense of hopefulness, questioning the one-sided, negative approach to growing old.

As exemplified by the articles selected for publication in this volume, it seems not to be possible to analyse the notion of hope in isolation. Hope appears to be harboured and not abandoned despite difficulties or tragedies we face; it thus resides in people and their actions rather than in events. Hope can surge unexpectedly and then suddenly disappear. An event that raises one's hope may shatter someone else's. Taking the above into consideration, the articles portray the ephemerality, multifacetedness, and ambiguity of the concept of hope.

In the article Revisiting the Myth of Dunkirk: Lissa Evans's Their Finest Hour and a Half, Alicja Lasak examines whether this contemporary British historical novel conveys hopeful messages regarding national unity and opportunities for women to demonstrate their full potential in the face of the Second World War or rather offers hope only as a by-product of the process of mythologising historical events. Kinga Jęczmińska's article In Search of Hope in J.M. Coetzee's Diary of a Bad Year indicates that, in spite of the protagonist's pessimistic views, artistic creation is depicted as a source of comfort and an incentive to change one's life for the better. In her article 'Hope as the Engine for Imagining Utopia': A Dream of a World Beyond Gender, Magdalena Dziurzyńska argues that, as opposed to dystopian worlds grounded in gender essentialism, utopian worlds tend to offer "futuristic" hope through the concept of gender transcendence. Whereas Dorota Czerkies explains the meaning of hope in relation to the concept of reticence in Jean-Philippe Toussaint's novel Reticence.

The four articles contained within the pages of Part One of this issue illuminate various aspects of hope, analysing the benefits of entertaining and providing hope as well as the perils of combining it with myth or utopia. Another batch of articles on hope, originating from the above-mentioned conference, will be presented in the following issue of Studia Litteraria. This publication is aimed at inspiring scholars' interest in this topic and encouraging a debate on the representation and applications of hope in works of literature. 
The remaining articles also tackle hope as well as other issues mentioned in the thematic section. Both unsettling and hopeful aspects of the gender question feature in Kristina Voronstova's paper that discusses Poland as "commonplace setting in queer poetry practices and performances" by contemporary Russian poets Aleksandr Anashevich, Yaroslav Mogutin, Aleksandr Ilyanen and Ilya Danishevskiy. In his article 'German Kazan': Imagological Analysis of Guzel Yakhina's Literary Works Michael Kuhn demonstrates how thanks to offering a "German image" of her hometown, the Russian writer acts as a mediator between cultures, thereby calling for humanity, and a hopeful coexistence of different ethnicities in one shared space.

The Editors 